\title{
Use of cyanoacrylate to treat mucosal perforations during or after peroral endoscopic myotomy
}

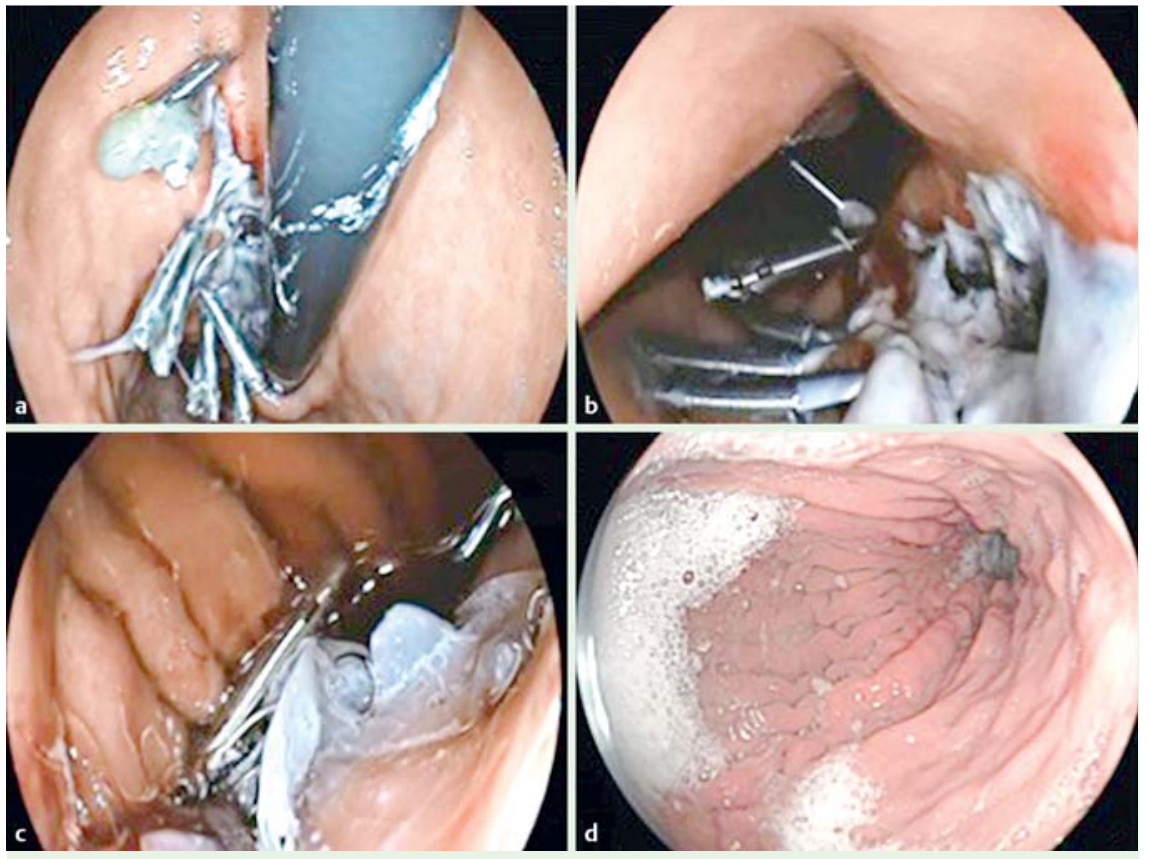

Fig. 1 Endoscopic view showing mucosal injury and treatment after uncomplicated peroral endoscopic myotomy (POEM). a Tearing at the gastric side of the POEM site, which could not be closed with clips (retroflexion view). b Mucosal perforation was seen at and $3 \mathrm{~cm}$ below the esophagogastric junction. Clip closure was unsuccessful. c Cyanoacrylate was applied successfully. d Endoscopy 8 months later showed only a small scar at the site.
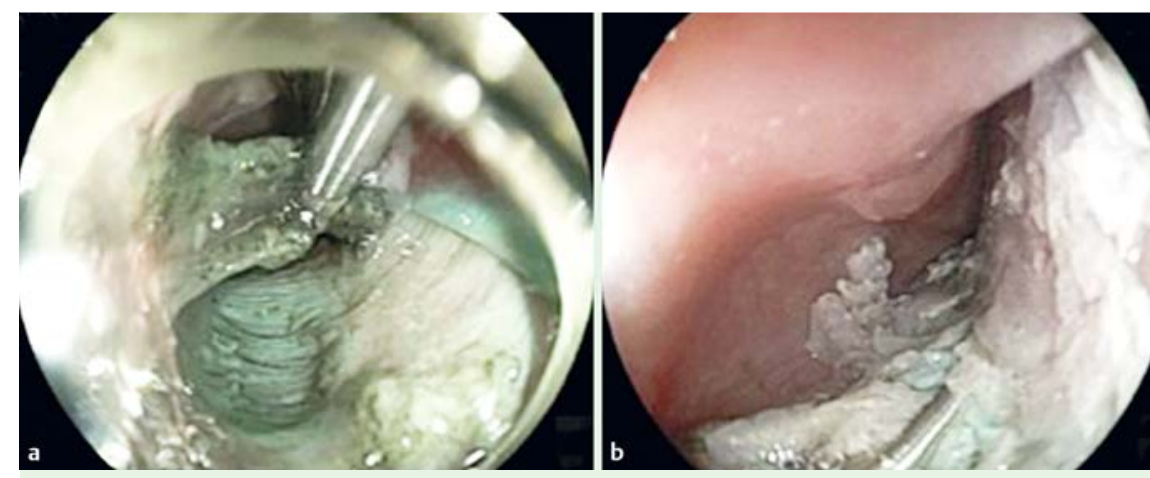

Fig. 2 Endoscopic view showing mucosal injury and treatment after difficult peroral endoscopic myotomy. a Tearing was observed at the entry site, and attempt at closure using clips was unsuccessful. b Cyanoacrylate was applied over this zone. c Endoscopy 1 month later showed only a small scar at this site.

Peroral endoscopic myotomy (POEM) is a safe and effective procedure for patients with achalasia [1]. Mucosal perforation is an inadvertent complication that is difficult or impossible to treat with standard clips [2]. Over-the-scope clips, endoluminal suturing devices, and fully covered stents have been used successfully $[3,4]$. Cyanoacrylate is used as a sealant because of its rapid solidification rate [5]. We report on three patients who were treated successfully with cyanoacrylate following failure of standard closure.

Case 1: a 26-year-old woman underwent an uncomplicated POEM procedure but presented nausea, vomiting, and tachycardia 48 hours later. On endoscopy, a wide mucosal injury was found at the esophagogastric junction and $3 \mathrm{~cm}$ below. An attempt at closure was unsuccessful. Therefore, $2 \mathrm{~mL}$ of undiluted cyanoacrylate was applied, and subsequent esopha-

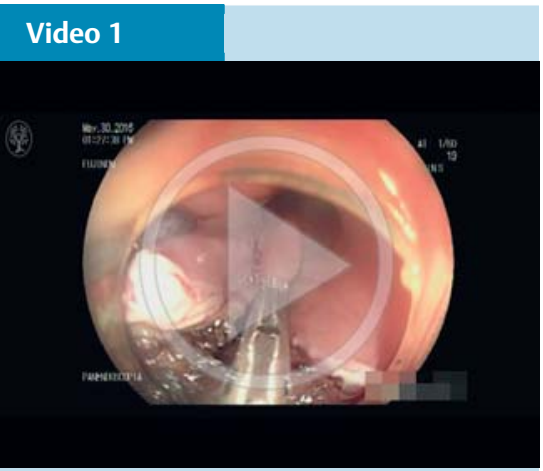

Cyanoacrylate use to seal mucosal perforations following peroral endoscopic myotomy. Conventional closure of the entry site with clips was performed. Esophagram 24 hours later showed contrast leaking into the submucosal tunnel at the level of the entry site. Conventional closure of this mucosal defect was unsuccessful. Cyanoacrylate was applied into the tunnel. No leak was observed on the subsequent esophagram. Endoscopy 1 month later showed adequate healing.

gram confirmed no leaks. The patient was discharged at 3 days later. Endoscopy 8 months later showed a small scar (๑ Fig. 1).

Case 2: a 51-year-old woman underwent POEM and showed contrast leak into the submucosal tunnel 24 hours after the procedure. The clips could not be rearranged to close the defect, and $2 \mathrm{~mL}$ of cyanoacrylate was applied successfully. The patient was discharged 48 hours later. Endoscopy confirmed normal mucosal healing ( $\bullet$ Video 1 ).

Case 3: a 40-year-old man underwent a difficult POEM procedure owing to the presence of submucosal fibrosis. He showed tearing of the mucosal entry site, which could not be closed with clips. Therefore, $3 \mathrm{~mL}$ of cyanoacrylate was applied successfully. The patient was discharged 48 hours later without complications ( Fig. 2 ).

This is the first report of the use of cyanoacrylate glue to seal mucosal defects during or after POEM in order to prevent leakage of esophageal contents into the tunnel, mediastinum or peritoneum. This polymer represents an inexpensive, feasible, and effective alternative when standard options fail. 
Endoscopy_UCTN_Code_TTT_1AO_2AI

Competing interests: None

\section{Oscar Víctor Hernández-Mondragón, Omar Michel Solórzano-Pineda, Gerardo Blanco-Velasco, Juan Manuel Blancas-Valencia}

Department of Endoscopy, Specialties Hospital, National Medical Center, Century XXI, Mexico City, México

\section{References}

1 Pannala $R, A b u$ B, Aslanian $H$ et al. Per-oral endoscopic myotomy. Gastrointest Endosc 2016; 86: $1051-1060$

2 Chandrasekhara V, Desilets D, Falk GW et al. The American Society for Gastrointestinal Endoscopy PIVI (Preservation and Incorporation of Valuable Endoscopic Innovations) on peroral endoscopic myotomy. Gastrointest Endosc 2015; 81: 1087-1100

3 Yang D, Zhang $Q$ Draganov P. Successful placement of a fully covered esophageal stent to bridge a difficult-to-close mucosal incision during peroral endoscopic myotomy. Endoscopy 2014; 46: E467-E468

4 Saxena P, Chavez YH, Kord Valeshabad A et al. An alternative method for mucosal flap closure during peroral endoscopic myotomy using an over-the-scope clipping device. Endoscopy 2013; 45: 579-581

5 Yasser M, Subhas B, Bradley A et al. Tissue adhesives: cyanoacrylate glue and fibrin sealant. Gastrointest Endosc 2013; 78: 209215

\section{Bibliography}

DOI http://dx.doi.org/ 10.1055/s-0042-117848 Endoscopy 2016; 48: E330-E331

(c) Georg Thieme Verlag KG

Stuttgart · New York

ISSN 0013-726X

\section{Corresponding author}

Oscar Víctor Hernández-Mondragón, MD

Department of Endoscopy

Specialties Hospital

National Medical Center

Century XXI

Cuauhtémoc Avenue 330

06700 México City

México

Fax: +52-55-55752379

mondragonmd@yahoo.co.uk 